\title{
Detecção de Erwinia psidii via enriquecimento em extrato de folhas de goiabeira e imunodifusão radial dupla
}

\author{
Ana Cristina O. Teixeira ${ }^{1}$, Marisa A.S.V. Ferreira ${ }^{1}$ \& Abi S.A. Marques ${ }^{2}$ \\ ${ }^{1}$ Departamento de Fitopatologia, Universidade de Brasília, 70.910-900, Brasília, DF, Brasil; ${ }^{2}$ Laboratório de Quarentena \\ Vegetal, Embrapa Recursos Genéticos e Biotecnologia, 70.770-970, Brasília, DF, Brasil.
}

Autor para correspondência: Marisa A.S.V. Ferreira, e-mail: marisavf@unb.br

\begin{abstract}
RESUMO
Uma das principais doenças que afetam a produção de goiaba no Brasil é a seca-dos-ponteiros, causada pela bactéria Erwinia psidii, cuja disseminação é favorecida por mudas contaminadas. O desenvolvimento de métodos diagnósticos mais eficazes poderia reduzir a disseminação da bactéria no país. Considerando a necessidade de se disponibilizar um método eficiente e simples para a detecção de $E$. psidii em material de propagação, foi objetivo desse trabalho produzir antissoros policlonais específicos contra a bactéria e desenvolver um método de detecção utilizando o enriquecimento da população bacteriana em extrato de folhas de goiabeira seguido de imunodifusão radial dupla. Um antissoro foi produzido contra a estirpe tipo da bactéria IBSBF 435 (ICMP 8426, NCPPB 3555), avaliado quanto à eficiência e especificidade e utilizado na determinação dos limiares de detecção da mesma. O antissoro As15-1 reagiu positivamente com todos as estirpes testadas de E. psidii, não reagindo com estirpes de outros gêneros e espécies de bactérias fitopatogênicas e apresentou reação cruzada com dois isolados não patogênicos da flora da goiabeira. O crescimento da população bacteriana no extrato de folhas foi observado após $12 \mathrm{~h}$ de incubação a partir de populações iniciais de $10^{3}, 10^{5}$ e $10^{7} \mathrm{ufc} / \mathrm{mL}$, até $60 \mathrm{~h}$. A partir de $12 \mathrm{~h}$, já foi possível detectar E. psidii por enriquecimento e imunodifusão radial nas amostras com populações iniciais de $10^{7} \mathrm{ufc} / \mathrm{mL}$ e a partir de $36 \mathrm{~h}$, detectou-se a bactéria mesmo em amostras com populações iniciais de $10^{3} \mathrm{ufc} / \mathrm{mL}$. Considerando a possibilidade de falsos positivos, é recomendável associar outros métodos diagnósticos ao método aqui proposto.
\end{abstract}

Palavras-chave: Psidium guajava, bacteriose da goiabeira, sorologia, diagnóstico.

\begin{abstract}
Detection of Erwinia psidii through enrichment in guava leaf extract and double radial immunodiffusion

One of the most important diseases affecting guava production in Brazil is bacterial blight, caused by the bacterium Erwinia psidii. Pathogen dissemination often occurs through contaminated propagating plant material. The development of more effective diagnostic methods may reduce pathogen dissemination in the country. Considering the need for a reliable and simple method for detecting the pathogen in plant material, the objectives of this study were to produce E. psdii-specific polyclonal antibodies and to develop a detection method using bacterial population enrichment on guava leaf extracts followed by double radial immunodiffusion. The antiserum was produced against the E. psidii type strain IBSBF 435 (ICMP 8426, NCPPB 3555) and its efficiency, specificity and sensitivity threshold were determined. The antiserum As15-1 was tested with strains of several plant-pathogenic bacteria and reacted positively with all strains of $E$. psidii, although cross reactions were detected with two non-pathogenic isolates from guava flora. Bacterial multiplication on leaf extracts was observed $12 \mathrm{~h}$ after incubation from initial populations of $10^{3}, 10^{5}$ and $10^{7} \mathrm{ufc} / \mathrm{mL}$, up to $60 \mathrm{~h}$. After $12 \mathrm{~h}$ it was already possible to detect E. psidii in samples with starting populations of $10^{7} \mathrm{cfu} / \mathrm{mL}$. After $36 \mathrm{~h}$, the enrichment technique allowed the detection of $E$. psidii using double radial immunodiffusion in samples with populations as low as $10^{3} \mathrm{cfu} / \mathrm{mL}$. Considering the possibility of false positives it is desirable to associate other diagnostic methods with the method proposed in this study.
\end{abstract}

Keywords: Psidium guajava, guava die-back, serology, diagnostic methods.

\section{INTRODUÇÃO}

Uma das principais doenças que afetam a produção de goiaba (Psidium guajava L.) no Brasil é a bacteriose causada por Erwinia psidii Rodrigues Neto et al. 1987, conhecida por seca-dos-ponteiros. Esta doença foi relatada,

Parte da Dissertação de Mestrado da primeira autora. Universidade de Brasília. Brasília DF. 2006. primeiramente, no Estado de São Paulo (Rodrigues Neto et al., 1987) e estudos posteriores sugerem que foi introduzida em outros estados através de mudas contaminadas assintomáticas (Oliveira et al., 2000; Uesugi et al., 2001; Romeiro et al., 2002). A certificação de mudas de goiabeira é baseada na análise subjetiva das plantas quanto ao aparecimento de sintomas. Entretanto, a análise visual não garante a aquisição de mudas livres do patógeno. Mesmo aparentemente sadias, mudas contaminadas apresentarão sintomas, aproximadamente, dois anos após sua instalação 
no pomar, tempo necessário para o início da frutificação (Gonzaga Neto et al., 2001).

Um dos fatores que favorece a diagnose preventiva, melhorando a sensibilidade na detecção de fitobactérias é o enriquecimento, o qual consiste em promover a multiplicação das células bacterianas presentes numa amostra por incubação em meios de cultura. Schaad et al. (1995) desenvolveram o método denominado Bio-PCR (reação da polimerase em cadeia) para detecção de Pseudomonas savastanoi pv. phaseolicola (Burk.) Gardan et al. 1992, em que as amostras foram cultivadas em meio de cultura antes da PCR. Cano \& Estrella (1997) confirmaram a confiabilidade e o poder de detecção desse método, identificando o patógeno em uma semente contaminada misturada a um lote de aproximadamente 4.000 sementes sadias. O mesmo princípio foi aplicado para outras fitobactérias como $P$. syringae Van Hall 1902, P. savastanoi pv. savastanoi (ex Smith 1908) Gardan et al. 1992 e Acidovorax avenae subsp. citrulli (Schaad et al. 1978) Willems et al. 1992, assim como no estudo de bactérias não fitopatogênicas (Bultreys \& Gheysen, 1999; Penyalver et al., 2000; Ghosh et al., 2004).

Os métodos sorológicos permitem a identificação rápida, simples e precisa de microrganismos, e têm como princípio a união de macromoléculas (anticorpo) ao mesmo tipo de indutor de sua produção (antígeno) (Tortora et al., 2003). Diversas técnicas sorológicas são usadas na detecção e identificação de bactérias fitopatogênicas (Singh et al., 2000; Lee et al., 2001; Sahin et al., 2003; Yorinori, et al., 2003; Carneiro Jr. et al., 2004), destacando-se ELISA (enzyme-linked immunosorbent assay), imunofluorescência (IF) e imunodifusão radial dupla (ID).

Apesar da simplicidade e rapidez, imunoensaios apresentam algumas desvantagens como: (a) não distinguem entre células viáveis e não viáveis e por isso não identificam o real perigo de disseminação de determinado patógeno; (b) os limiares de detecção são elevados e (c) amostras contendo alta concentração de contaminantes saprofíticos podem sofrer interferências devido à competição desses com o patógeno alvo (Saettler et al., 1989).

O método de ID (Ouchterlony, 1958) é realizado em gel de agar ou agarose, onde pode ser observada uma linha de precipitação entre os orifícios, caso haja especificidade entre antígeno e anticorpo. Este método foi utilizado para a detecção de fitobactérias, como $P$. syringae pv. tabaci (Wolf \& Foster 1917) Young et al. 1978 (Alvarez \& Marques, 2004; Spitali et al., 2007). Estudos preliminares para a detecção de E. psidii através de ID, em mudas assintomáticas de goiabeira, foram realizados por Ribeiro et al. (2005).

Considerando a necessidade de se estabelecer um método eficiente e simples para a detecção de E. psidii, o presente trabalho teve como objetivo produzir um antissoro específico contra esse patógeno e desenvolver um método de detecção por imunodifusão radial dupla, aumentando a sua sensibilidade pelo enriquecimento em meio natural obtido pela maceração de folhas de goiabeira.

\section{MATERIAL E MÉTODOS}

Quarenta e sete estirpes de E. psidii foram utilizadas, sendo 16 provenientes da Coleção de Culturas de Fitobactérias do Instituto Biológico de São Paulo (IBSBF); 26 da coleção de trabalho da Unidade de Bacteriologia, Laboratório de Quarentena Vegetal (LQV) da Embrapa Recursos Genéticos e Biotecnologia e cinco da coleção do Laboratório de Fitopatologia, Departamento de Fitopatologia da Universidade de Brasília (Tabela 1).

\section{Produção e avaliação de antissoro policlonal anti-Erwinia psidii}

Um antissoro policlonal foi produzido contra a estirpe tipo de $E$. psidii, IBSBF 435 (ICMP 8426, NCPPB 3555) e avaliado quanto à sua eficiência e especificidade. Para a produção do antissoro, a bactéria foi cultivada em meio sólido 523 de Kado \& Heskett (1970), por 48 h a 28 ${ }^{\circ} \mathrm{C}$. Dessa cultura, foi preparada a suspensão-antígeno a \pm $10^{8} \mathrm{ufc} / \mathrm{mL}$, cuja concentração foi ajustada pela medida da transmitância. Foi injetado $1,0 \mathrm{~mL}$ da suspensão bacteriana acima descrita, fixada com formol a $0,5 \%$, emulsificada com $1,0 \mathrm{~mL}$ de adjuvante de Freund (15\% de Mamide monoleate e $85 \%$ de óleo de parafina) em coelhos de três meses, da raça Nova Zelândia. Foram realizadas quatro aplicações intramusculares na coxa posterior do coelho, a intervalos de sete dias entre aplicações. Para a primeira aplicação utilizou-se o adjuvante completo, que contém BCG (vacina, linhagem avirulenta do bacilo da tuberculose), com o intuito de estimular uma resposta mais rápida do sistema imunológico do animal e, para as aplicações seguintes, o adjuvante incompleto, sem BCG.

A sangria na veia marginal da orelha do coelho foi realizada para avaliação do título do antissoro, sete dias após a última injeção, de acordo com protocolo de Ausubel et al. (1999). O antissoro foi diluído em solução salina tampão fosfato (PBS), nas proporções de 1:1, 1:2, 1:4, 1:8, 1:16, 1:32 e 1:64, e avaliado pelo método de imunodifusão radial dupla. Sobre uma lâmina de microscopia, foi preparada camada de agarose a $1 \%$ em PBS com azida sódica (1\%), com $2 \mathrm{~mm}$ de espessura, aproximadamente. Após solidificação foram feitos furos radiais com o auxílio de uma roseta de aço inox. No furo central foram colocados $20 \mu \mathrm{L}$ da suspensão bacteriana da estirpe tipo a uma concentração maior que $10^{8}$ ufc/mL e nos furos periféricos foram colocados $20 \mu \mathrm{L}$ do antissoro produzido (designado As15), na ordem crescente das diluições. As lâminas foram mantidas em câmara úmida por $24 \mathrm{~h}$ para se verificar a formação de bandas de precipitação pela reação antígeno-anticorpo.

Após a obtenção do título satisfatório do antissoro, o sangue foi coletado em frasco de vidro $( \pm 40 \mathrm{~mL})$, mantido por uma hora a temperatura ambiente e aquecido a $37^{\circ} \mathrm{C}$ por $30 \mathrm{~min}$, após o coágulo ter sido descolado das paredes laterais do frasco. Em seguida, foi mantido sob refrigeração $\left(4^{\circ} \mathrm{C}\right)$ por $12-18 \mathrm{~h}$. Após esse período, o soro foi aspirado e centrifugado a $6.000 \mathrm{~g}$ por $15 \mathrm{~min}$, descartando-se o coágulo. 
TABELA 1 - Designação, origem e reação ao antissoro As15-1 por imunodifusão radial dupla das estirpes de Erwinia psidii utilizadas neste estudo

\begin{tabular}{|c|c|c|c|}
\hline Estirpe & Procedência & Ano de coleta & ID $^{\mathbf{a}}$ \\
\hline IBSBF $^{\mathrm{b}} 435^{\mathrm{c}}, 446^{\mathrm{d}}$ & Valinhos - SP & 1982 & $+^{\mathrm{g}},+$ \\
\hline IBSBF $453,454,452$ & Valinhos - SP & 1983 &,,+++ \\
\hline IBSBF 493 & Itariri - SP & 1984 & + \\
\hline IBSBF 954 & SP & 1992 & + \\
\hline IBSBF 1347 & Brazlândia - DF & 1997 & + \\
\hline IBSBF 1461 & Urupês - SP & 1999 & + \\
\hline IBSBF 1480 & Santa Tereza - ES & 2000 & + \\
\hline IBSBF 1523 & Carlopólis - PR & 2000 & + \\
\hline IBSBF 1574 & $\mathrm{SP}$ & 2001 & + \\
\hline IBSBF 1575 (Emb.A 18-7e) & Brazlândia - DF & 2000 & + \\
\hline IBSBF 1576 (Emb.B 67-1) & Brazlândia - DF & 2001 & + \\
\hline IBSBF 1577 (Emb.B 74-1) & Brazlândia - DF & 2001 & + \\
\hline IBSBF 1579 (Emb.B 78-1) & Brazlândia - DF & 2001 & + \\
\hline Emb.C 75-1, 76-1, 82-1 & $\begin{array}{l}\text { Brazlândia - DF } \\
\text { (Propriedade 1) }\end{array}$ & 2002 &,,+++ \\
\hline Emb.C 133-1, 134-1, 140-1, 142-2 & $\begin{array}{l}\text { Brazlândia - DF } \\
\text { (Propriedade 2) }\end{array}$ & 2002 &,,,++++ \\
\hline Emb.C 148-2, 150-1, 151-2, 153-1 & $\begin{array}{l}\text { Brazlândia - DF } \\
\text { (Propriedade 3) }\end{array}$ & 2002 &,,,++++ \\
\hline Emb.C 294-1, 295-3, 296-1, 299-3 & $\begin{array}{l}\text { Brazlândia - DF } \\
\text { (Propriedade 4) }\end{array}$ & 2002 &,,,++++ \\
\hline Emb.C 338-2, 339.1, 342-1, 343-2, 345-2 & $\begin{array}{l}\text { Brazlândia - DF } \\
\text { (Propriedade 5) }\end{array}$ & 2002 &,,,,+++++ \\
\hline Emb.C 400-3 & $\begin{array}{l}\text { Brazlândia - DF } \\
\text { (Propriedade 6) }\end{array}$ & 2002 & + \\
\hline Emb.C 421-2, 424-1, 432-1, 435-2, 439-3 & $\begin{array}{l}\text { Brazlândia - DF } \\
\text { (Propriedade 7) }\end{array}$ & 2002 &,,,,+++++ \\
\hline $\mathrm{UnB}^{\mathrm{f}} 1285,1286$ & $\begin{array}{l}\text { Brazlândia - DF } \\
\text { (Propriedade 9) }\end{array}$ & 2004 &,++ \\
\hline UnB 1287 & $\begin{array}{l}\text { Brazlândia - DF } \\
\text { (Propriedade 2) }\end{array}$ & 2005 & + \\
\hline UnB 1288 & $\begin{array}{l}\text { Brazlândia - DF } \\
\text { (Propriedade 11) }\end{array}$ & 2005 & + \\
\hline UnB 1289 & $\begin{array}{l}\text { Brazlândia - DF } \\
\text { (Propriedade 12) }\end{array}$ & 2005 & + \\
\hline
\end{tabular}

${ }^{\mathrm{a} R e a c ̧ a ̃ o ~ d e ~ i m u n o d i f u s a ̃ o ~ r a d i a l ~ d u p l a ~ e m ~ a g a r o s e, ~ u t i l i z a n d o-s e ~ o ~ a n t i s s o r o ~ A 15-1 ; ~}{ }^{\mathrm{b}}$ Coleção de Culturas

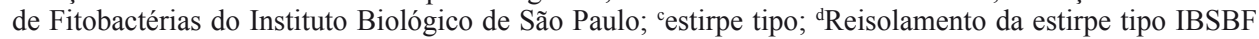
435; ${ }^{\circ}$ Coleção de Fitobactérias: Laboratório de Quarentena vegetal - Unidade de Bacteriologia, Embrapa Recursos Genéticos e Biotecnologia; ${ }^{\mathrm{f} U n i v e r s i d a d e ~ d e ~ B r a s i ́ l i a, ~ C o l e c ̧ a ̃ o ~ d e ~ B a c t e ́ r i a s ~ F i t o p a t o g e ̂ n i c a s ~}$ do Departamento de Fitopatologia; 'Reação de imunodifusão positiva, com a formação de banda de precipitação.

O sobrenadante foi colocado em um frasco esterilizado, adicionando-se azida sódica para uma concentração final de $0,025 \%$. Ao antissoro foi acrescentada glicerina na proporção $1: 1$ e estocado sob refrigeração $\left(4^{\circ} \mathrm{C}\right)$. O material dessa última coleta foi designado As15-1, não sendo misturado ao da primeira coleta (titulação).

A especificidade do antissoro foi determinada frente a 47 estirpes de E. psidii (Tabela 1) e 10 estirpes de outros gêneros e espécies de bactérias fitopatogênicas: Acidovorax avenae subsp. avenae (Emb.A 226-1), A. avenae subsp. citrulli (Aac 1-12), Clavibacter michiganensis subsp. michiganensis (CBCEN 10), Pectobacterium carotovorum subsp. carotovorum (Emb.A 243-1), Erwinia sp. (Emb. A 12-5, isolada de milho), Pseudomonas syringae pv. tabaci (Emb.C 478), P. syringae pv. tomato (CNPH 45), Xanthomonas axonopodis pv. phaseoli (Emb.A 62-6), X. axonopodis pv. sesami (Emb.C 333-1) e X. campestris pv. campestris (Emb.C 481-1). Além disso, testou-se também o antissoro frente a 10 isolados bacterianos saprofíticos da flora natural da goiabeira, obtidos de folhas, pedúnculos de frutos mumificados ou da extremidade dos brotos de goiabeira. Embora não tenham sido identificados, esses isolados não se mostraram patogênicos à goiabeira. Para os ensaios com ID, utilizou-se o método descrito acima, mas posicionando-se 
o antissoro no orifício central e as suspensões bacterianas nos orifícios periféricos. A estirpe tipo (IBSBF 435) foi regularmente usada como controle positivo e PBS como controle negativo.

\section{Determinação dos limiares de detecção de Erwinia psidii}

$\mathrm{O}$ enriquecimento bacteriano foi conduzido em extrato de folhas de goiabeira da cv. Paluma. Folhas jovens (1 g), obtidas de mudas sadias mantidas em casa de vegetação, foram acondicionadas em sacos plásticos esterilizados, recebendo 3,5 $\mathrm{mL}$ das suspensões bacterianas em diferentes concentrações. As folhas foram levemente esmagadas com pistilo de cerâmica, com o intuito de permitir que a suspensão bacteriana entrasse em contato com o extrato das mesmas. As temperaturas de incubação foram 29 a $31^{\circ} \mathrm{C}$ durante $\mathrm{o}$ dia e 26 a $27^{\circ} \mathrm{C}$ durante a noite. Foram realizadas quatro repetições, para cada tratamento, os quais corresponderam às concentrações de inóculo de $\pm 10^{7}, 10^{5}$ e $10^{3} \mathrm{ufc} / \mathrm{mL}$. Utilizou-se $250 \mu \mathrm{L}$ da mistura suspensão bacteriana-extrato de folhas para a diluição seriada e o plaqueamento em meio sólido 523. A estimativa da evolução populacional de $E$. psidii no extrato das folhas de goiabeira foi realizada durante $60 \mathrm{~h}$, a intervalos de $12 \mathrm{~h}$. Nos mesmos intervalos, o limiar de deteç̧ão por imunodifusão radial dupla foi determinado, conforme descrito anteriormente, utilizando-se $20 \mu \mathrm{L}$ da mistura suspensão-extrato.

\section{RESULTADOS E DISCUSSÃO}

Um antissoro policlonal específico para E. psidii foi produzido, usando-se como antígeno a estirpe tipo (IBSBF 435). O título obtido, de 1:16 da concentração original, foi satisfatório para o método de imunodifusão radial dupla (Figura 1A).

Submetido ao teste de especificidade, o antissoro, identificado como As15-1, apresentou reação antígenoantissoro positiva para a estirpe tipo, assim como para as demais estirpes de E. psidii, previamente identificadas e usadas como referência (Tabela 1). Não houve reação com as estirpes de fitobactérias de outros gêneros, espécies ou patovares testados (Figura 1B). Entretanto, houve reação cruzada com dois isolados saprofíticos da flora bacteriana da goiabeira, indicando a presença de epítopos em comum. As reações cruzadas são freqüentes com antissoros policlonais (Trigalet et al., 1978) e, embora possam produzir resultados falso-positivos, não invalidam o diagnóstico, sobretudo quando mais de uma técnica é usada para um diagnóstico conclusivo.

A ID é um método simples e rápido, mas pouco sensível para uso rotineiro em detecção de fitobactérias, pois é necessária uma concentração elevada da bactéria alvo para que a reação seja visível. Estudos preliminares, utilizando enriquecimento aliado à sorologia para detecção, foram realizados por Ribeiro et al. (2005), quando se verificou que a multiplicação de E. psidii em folhas de goiabeira esmagadas possibilitava sua detecção através de ID. Contudo, a população final detectável não foi quantificada.

As populações bacterianas e os resultados da ID a cada intervalo de $12 \mathrm{~h}$ (Tabela 2) e a curva do crescimento bacteriano no extrato das folhas durante $60 \mathrm{~h}$ (Figura 2) são apresentadas. Nenhum dos tratamentos apresentou reação sorológica positiva no T0 (tempo zero). A partir de 12 h, já foi possível detectar E. psidii nas amostras com populações iniciais de $10^{7} \mathrm{ufc} / \mathrm{mL}$. Neste tratamento foi observado crescimento bacteriano em todas as repetições, as quais atingiram concentração de $10^{8} \mathrm{ufc} / \mathrm{mL}$, com $25 \%$ de resultado positivo para ID. Para os demais tratamentos, após $12 \mathrm{~h}$ de incubação, houve crescimento bacteriano, mas não houve detecção por ID. Entretanto, a partir de 36 h, detectou-se a bactéria mesmo nas amostras com populações iniciais de $10^{3} \mathrm{ufc} / \mathrm{mL}$.

De acordo com os resultados obtidos, se a contaminação de materiais de propagação a serem examinados correspondesse a uma população inicial de $E$. psidii de $10^{7}$ ufc/g de tecido, seria possível a detecção da bactéria em $25 \%$ das amostras dentro de $12 \mathrm{~h}$ e após $36 \mathrm{~h}$ seria possível concluir o diagnóstico. Se a contaminação dos materiais fosse de $10^{5}$ ufc/g de tecido, a detecção da bactéria
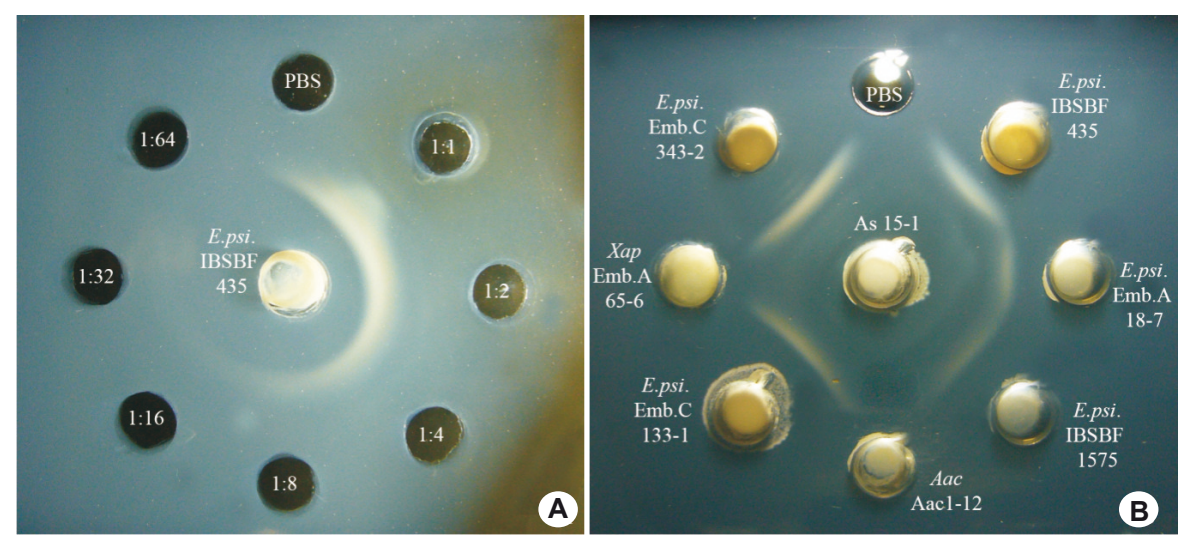

FIG. 1 - Teste de imunodifusão radial dupla para avaliação do antissoro As15, produzido para identificação de Erwinia psidii: A - titulação do antissoro com a bactéria homóloga (IBSBF 435), onde os valores nos poços periféricos representam a diluição do antissoro; $\mathrm{B}$ - avaliação da especificidade do antissoro, observandose a banda de precipitação (reação positiva) para as estirpes de E. psidii (E.psi.) e ausência de reação com estirpes de Xanthomonas axonopodis pv. phaseoli (Xap), Acidovorax avenae subsp. citrulli (Aac) e com o controle negativo (PBS).

Tropical Plant Pathology 33 (3) May - June 2008 
TABELA 2 - Crescimento populacional de Erwinia psidii (estirpe Emb.A 18-7) a partir de diferentes concentrações iniciais, em extrato de folhas de goiabeira e limiares de detecção da bactéria por imunodifusão radial dupla

\begin{tabular}{|c|c|c|c|c|c|c|c|c|c|c|c|c|}
\hline \multirow{3}{*}{$\begin{array}{l}\text { Concentração } \\
\text { inicial (ufc/mL) }\end{array}$} & \multicolumn{12}{|c|}{ Tempo (h) } \\
\hline & \multicolumn{2}{|l|}{$\mathbf{0}$} & \multicolumn{2}{|l|}{12} & \multicolumn{2}{|l|}{24} & \multicolumn{2}{|l|}{36} & \multicolumn{2}{|l|}{48} & \multicolumn{2}{|l|}{60} \\
\hline & Populaçã & ${ }^{1} \mathrm{ID}^{2}$ & População & ID & População & ID & População & ID & População & ID & População & ID \\
\hline $10^{7}$ & $3,3 \times 10^{7}$ & 0 & $2,8 \times 10^{8}$ & 25 & $2,7 \times 10^{8}$ & 75 & $2,9 \times 10^{8}$ & 100 & $3,6 \times 10^{8}$ & 100 & $4,0 \times 10^{8}$ & 100 \\
\hline $10^{5}$ & $6,7 \times 10^{4}$ & 0 & $3,2 \times 10^{6}$ & 0 & $2,4 \times 10^{7}$ & 25 & $2,7 \times 10^{8}$ & 75 & $6,6 \times 10^{8}$ & 75 & $3,4 \times 10^{8}$ & 75 \\
\hline $10^{3}$ & $5,2 \times 10^{2}$ & 0 & $8,3 \times 10^{4}$ & 0 & $2,6 \times 10^{6}$ & 0 & $6,2 \times 10^{8}$ & 50 & $4,2 \times 10^{8}$ & 50 & $7,1 \times 10^{8}$ & 75 \\
\hline
\end{tabular}

${ }^{1}$ População bacteriana (ufc/mL), média de quatro repetições; ${ }^{2}$ Porcentagem de repetições com resultado positivo para imunodifusão radial dupla em gel de agarose.

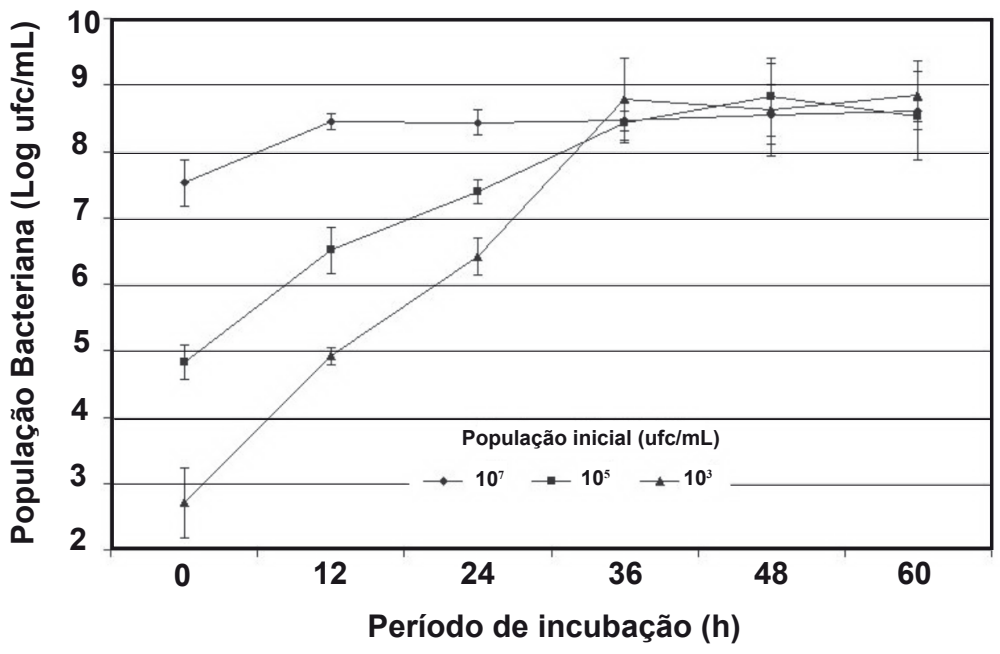

se daria após 24 h de incubação em $25 \%$ dos casos. Com um nível de contaminação de $10^{3} \mathrm{ufc} / \mathrm{g}$ de tecido, as primeiras reações positivas em ID ocorreriam após $36 \mathrm{~h}$.

A concentração da suspensão bacteriana reativa com o anticorpo anti-E. psidii esteve sempre em torno de $10^{8} \mathrm{ufc} / \mathrm{g}$ de tecido ( $75 \%$ das reações positivas). Observase, entretanto, que em algumas repetições, as suspensões apresentando igual concentração não apresentaram reação positiva em ID, o que evidencia a possível ocorrência de falsos negativos. Por outro lado, houve reação positiva de uma suspensão a $10^{5} \mathrm{ufc} / \mathrm{mL}$ após $60 \mathrm{~h}$. Como as técnicas moleculares e sorológicas podem detectar tanto células viáveis quanto não viáveis (Saettler et al., 1989, Theodoro \& Maringoni, 2002) é possível que, nesse caso, um certo número de células tivesse perdido a viabilidade.

As divergências observadas para a reação de ID, com suspensões de mesma concentração, podem ser explicadas pela inibição da reação por substâncias presentes no extrato das folhas. O esmagamento de tecidos pode provocar a liberação
FIG. 2 - Crescimento populacional de Erwinia psidii em extrato de folhas de goiabeira maceradas, durante o período de $60 \mathrm{~h}$. Cada ponto representa a média das quatro repetições e as barras verticais representam o erro padrão da média. de substâncias que possuam atividade antimicrobiana, sendo que em folhas de goiabeira há relato de uma atividade moderada contra bactérias gram- negativas (Nair \& Chanda, 2007). É possível que, depois de 48 h, houvesse no extrato de folhas, maior concentração de substâncias derivadas da degradação das mesmas, como o quinino, que poderia interferir na reação antígeno-anticorpo.

Pode-se concluir que, independente do nível de contaminação, E. psidii pode ser detectada em material vegetativo de goiabeira no intervalo de 36 a $60 \mathrm{~h}$ por ID após enriquecimento, período em que a maioria das populações, foi reativa com o antissoro policlonal produzido contra a bactéria. Entretanto, a possibilidade de falsos positivos deve ser considerada, tendo em vista as reações cruzadas observadas com dois isolados bacterianos da flora da goiabeira. Assim, é recomendável a utilização de mais de um método para confirmação dos resultados. Por outro lado, ao final das $60 \mathrm{~h}$ de análise, a porcentagem de detecção por ID permaneceu em torno de $75 \%$ em dois dos tratamentos. 
Nesses casos, acredita-se que um período maior de incubação poderia resultar na detecção da bactéria em 100\% das amostras, reduzindo significativamente a ocorrência de falsos negativos.

A disponibilização de um método simples e rápido, que possa ser usado em laboratórios pouco equipados, é vantajosa. $\mathrm{O}$ método de enriquecimento bacteriano em extrato de folhas de goiabeira aliado à imunodifusão radial dupla, reúne rapidez e baixo custo. Com o aumento da população pelo enriquecimento, a baixa sensibilidade da ID é contornada, podendo ser utilizada na análise de mudas, caso sejam portadoras de E. psidii em baixas concentrações $\left(10^{3} \mathrm{ufc} / \mathrm{mL}\right)$. Apesar desse aporte na redução do limiar de detecção da ID, o processo pode ser melhorado pela purificação do antissoro e os falsos negativos podem ser reduzidos pelo uso concomitante de outros métodos para diagnose, além de modificações no preparo do extrato de folhas, visando reduzir a ação de possíveis inibidores.

Os resultados obtidos no presente estudo poderão ser utilizados por técnicos da Defesa Vegetal para a certificação de viveiros. Isto contribuiria, certamente, para a redução da disseminação da bactéria para novos pomares, outros estados ou regiões produtores de goiaba no Brasil, como a região Nordeste que, até o momento, encontra-se livre da doença. Da mesma forma, o desenvolvimento de outras ferramentas, tais como as moleculares, contribuirão para maior eficiência da diagnose precoce da seca-dos-ponteiros.

\section{AGRADECIMENTOS}

Ao Conselho Nacional de Desenvolvimento Científico e Tecnológico - CNPq pelo apoio financeiro e concessão da bolsa de Mestrado à primeira autora; a Joanice P.S. Damasceno e Alexandre P. Mendes, do Laboratório de Quarentena Vegetal da Embrapa Recursos Genéticos e Biotecnologia por sua valiosa colaboração na execução dos experimentos; ao Dr. Júlio Rodrigues Neto, curador da Coleção de Culturas de Fitobactérias do Instituto Biológico de São Paulo (IBSBF) e ao Professor Carlos H. Uesugi, do Departamento de Fitopatologia da UnB, pela cessão das estirpes; ao Paulo Augusto C. Marinho e Wesley R. Souza, pela edição das imagens.

\section{REFERÊNCIAS BIBLIOGRÁFICAS}

Alvarez E, Marques ASA (2003) Caracterização molecular, sorológica e nutricional de isolados de Pseudomonas syringae pv. tabaci provenientes de fumo, feijão e soja: desenvolvimento de metodologia para o diagnóstico do fogo selvagem. Brasília, DF. Embrapa Recursos Genéticos e Biotecnologia, Boletim de Pesquisa e Desenvolvimento, 52.

Ausubel FM, Brent R, Kingston RE, Moore DD, Seidman JG, Smith JA, Struhl K (1999) Short protocols in molecular biology. $4^{\text {th }}$ Ed. John Wiley \& Sons Inc.
Bultreys A, Gheysen I (1999) Biological and molecular detection of toxic lipodepsipeptide-producing Pseudomonas syringae strains and PCR identification in plants. Applied and Environmental Microbiology 65:1904-1909.

Cano GM, Estrella LH (1997) A simple and efficient PCR method for the specific detection of Pseudomonas syringae pv. phaseolicola in bean seeds. World Journal of Microbiology \& Biotechnology 13:463-437.

Carneiro Junior JB, Silveira SF, Souza Filho GA, Olivares FL, Giglioti EA (2004) Especificidade de anti-soro policlonal a Leifsonia xyli subsp. xyli. Fitopatologia Brasileira 29:614-619.

Ghosh M, Verma SC, Mengoni A, Tripathi AK (2004) Enrichment and identification of bacteria capable of reducing chemical oxygen demand of anaerobically treated molasses spent wash. Journal of Applied Microbiology 96:1278-1286.

Gonzaga Neto L, Soares JM, Teixeira AHC, Moura MSB (2001) Goiaba: produção - aspectos técnicos. Petrolina, PE. Embrapa Semi-Árido, Brasília, DF. Embrapa Informação Tecnológica (Frutas do Brasil, 17).

Kado CI, Heskett MG (1970) Selective media for isolation of Agrobacterium, Corynebacterium, Erwinia, Pseudomonas, and Xanthomonas. Phytopathology 60:969-976.

Lee IM, Lukaesko LA, Maroon CJM (2001) Comparison of Dig-labeled PCR, Nested PCR, and ELISA for the detection of Clavibacter michiganensis subsp. sepedonicus in field-grown potatoes. Plant Disease 85:261-266.

Nair R, Chanda S (2007) In-vitro antimicrobial activity of Psidium guajava L. leaf extracts against clinically important pathogenic microbial strains. Brazilian Journal of Microbiology 38:452-458.

Oliveira JR, Ventura JA, Silva IT, Costa H (2000) Ocorrência da bacteriose da goiabeira, causada por Erwinia psidii, no Estado do Espírito Santo. Fitopatologia Brasileira 25(Supl):328.

Ouchterlony O (1958) Diffusion-in-gel methods for immunological analysis. Progress Allergy 5:1-78.

Penyalver R, Garcia A, Ferrer A, Bertolini E, Lopez MM (2000) Detection of Pseudomonas savastanoi pv. savastanoi in olive plants by enrichment and PCR. Applied and Environmental Microbiology 66:2673-2677.

Ribeiro RG, Melo LA, Santos JP, Mendes AP, Martins OM, Marques ASA (2005) Avaliação preliminar de técnicas sorológicas na detecção de Erwinia psidii em mudas de goiabeiras assintomáticas. Fitopatologia Brasileira 30(Supl):57.

Rodrigues Neto J, Robbs CF, Yamashiro TA (1987) A bacterial disease of guava (Psidium guajava) caused by Erwinia psidii sp. nov. Fitopatologia Brasileira 12:345-350.

Romeiro RS, Batista UG, Barbosa JG \& Rodrigues Neto J 2002 Situação e perspectivas de controle da morte das pontas da goiabeira (Erwinia psidii) em Minas Gerais - Relato de um caso. Revista Ceres 49:329-334.

Saettler AW, Schaad NW, Roth DA (1989) (Eds.) Detection of bacteria in seed and other planting material. Saint Paul MN. APS Press.

Sahin F, Abbasi PA, Ivey MLL, Zhang J, Miller SA (2003) Diversity among strains of Xanthomonas campestris pv. vitians from lettuce. Phytopathology 93:64-70.

Schaad NW, Cheong SS, Tamaki S, Hatziloukas E, Panopoulos NJ 
(1995) A combined biological and enzymatic amplification (BIOPCR) technique to detect Pseudomonas syringae pv. phaseolicola in bean seed extracts. Phytopathology 85:243-248.

Singh U, Trevors CM, de Boer SH, Janse JD (2000) Fimbrialspecific monoclonal antibody- based ELISA for European potato strains of Erwinia chrysanthemi and comparison to PCR. Plant Disease 84:443-448.

Spitali M, Smith ARW (2007) Structure of the lipopolysaccharide side chain of Pseudomonas syringae pv. tabaci strain NCPPB 79 (=CFBP1615), in relation to O-serogroup. Journal of Phytopathology 155:1-7.

Theodoro GF, Maringoni AC (2002) Sobrevivência de Xanthomonas axonopodis pv. manihotis em manipueira sob condições ambientais.
Pesquisa Agropecuária Brasileira 37:945-953.

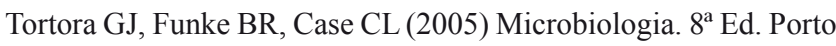
Alegre RS. Artmed.

Trigalet A, Samson R, Coléno A (1978) Problems related to the use of serology in phytobacteriology. Proceedings, 4th International Conference on Plant Pathogenic Bacteria, Angers. pp. 271-288.

Uesugi CH, Melo Filho PA, Lima ML, Moraes CA, Tomita CK, Café Filho AC, Ueno B (2001) Ocorrência de Erwinia psidii em goiabeira no Distrito Federal. Summa Phytopathologica 27:118. (Resumo)

Yorinori MA, Ribas AF, Ueno B, Massola Jr NS, Leite Jr RP (2003) Detecção de Xylella fastidiosa em germoplasma de cafeeiro. Fitopatologia Brasileira 28:427-430.

Recebido 18 Agosto 2007 - Aceito 14 Maio 2008 - TPP 7089 Editor Associado: Valmir Duarte 